\title{
A case study of non-traditional treatments for the control of wheat stem rust disease
}

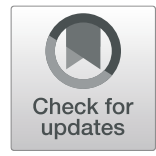

\author{
Reda I. Omara ${ }^{1}$, Tarek A. Essa ${ }^{1}$, Amal A. Khalil ${ }^{1}$ and Mohsen M. Elsharkawy ${ }^{2^{*}}$ (D)
}

\begin{abstract}
Wheat stem rust causes by Puccinia graminis f. sp. tritici is a serious threat to wheat production all over the world. This study evaluated the efficacy of Bacillus subtilis, B. polymyxa and B. megaterium, Eugenol and leaf extract of Artemisia cina against the disease, and the involved mechanisms in disease resistance. B. subtilis and Eugenol treatments inhibited spore germination and increased incubation and latent periods than other treatments. Additionally, the lowest infection type, pustule length and pustule width, and receptivity (no. of pustules) were recorded in case of B. subtilis and Eugenol treatments compared with the check control. The best results in disease assessment were achieved by foliar spray application $24 \mathrm{~h}$ before and after inoculation. Abnormalities, lysis, collapse, and shrinking of urediniospores were recorded in treated leaves. The activities of antioxidant defense enzymes, i.e., catalase (CAT), peroxidase (POX), and polyphenoloxidase (PPO), were significantly increased in B. subtilis and Eugenol treatments. On the other hand, electrolyte leakage was decreased. The active compounds in $B$. subtilis were revealed by utilizing GC-MS analysis.
\end{abstract}

Keywords: Wheat, Stem rust, Puccinia graminis f. sp. tritici, Bioagents, Enzyme activities, Electrolyte leakage, GC-MS

\section{Background}

In Egypt, wheat is liable to attack by many diseases such as rusts, powdery mildew, and smut. Wheat rusts are still the main biotic stress, which affect the yield quantity and quality of most wheat cultivars under Egyptian conditions (Omara and Abdelaal 2018). Stem rust, caused by Puccinia graminis f. sp. tritici, is one of the 3 main rusts attacking wheat plants in Egypt. Disease severity increases in the absence of resistance varieties, and the disease outbreak may occur suddenly, particularly with the continuous genetic changes of host pathogen interactions (Omara et al. 2017).

The main strategy for stem rust management depends on planting resistant varieties, early detection of the disease, and successful application of effective fungicides at the right time with sufficient doses. Although several fungicides are effective for disease control, but they may have a negative impact on human health and safety due

\footnotetext{
* Correspondence: mohsen.abdelrahman@agr.kfs.edu.eg

${ }^{2}$ Agricultural Botany Department, Faculty of Agriculture, Kafrelsheikh

University, Kafr Elsheikh 33516, Egypt

Full list of author information is available at the end of the article
}

to the persistence of residues and exposure risks (Hermas et al. 2008). The intensive repeated application of fungicides causes environmental pollution and leads to the development of new pathogen strains, which could be more aggressive if they have resistance against the routinely used fungicides (Abd El-Moneim et al. 2011). It was reported that the application of biological control treatments, such as Bacillus subtilis, B. polymyxa, B. circilance, Pseudomonas fluorescens, and Trichoderma harzianum, and some chemical inducers such as Eugenol, Allicin, and Fulvic acid were effective in management strategies against different pathogens (ElSawy et al. 2016 and Omara et al. 2019), particularly against P. graminis (Abd El-Moneim et al. 2011). Several Bacillus spp. are antagonistic to plant pathogenic fungi due to the production of at least 66 different antibiotic compounds (Ferreira et al. 1991). Eugenol is an active ingredient that was used successfully in the elimination of many plant pathogens. Eugenol treatment reduced rust severity (\%) and AUDPC at adult stage by inhibition of $P$. striiformis urediniospores germination, reduction of incubation and latent periods at the seedling stage 
(El-Sawy et al. 2016). Similarly, the application of Artemisia cina was effective in the control of wheat leaf rust disease through increased incubation and latent periods and prevention of urediniospores germination. Therefore, successful and safe approaches in plant protection, using biological and natural inducers, are required (Omara et al. 2015 and 2019).

Plant infection with different pathogens is related with the accumulation of reactive oxygen species (ROS). So, antioxidant defense system seems to be a common response to oxidative stress (Omara and Abdelaal 2018). After pathogen attack, several antioxidant enzymes such as peroxidase, polyphenol oxidase, and catalase start its function by decreasing ROS levels and elimination of detrimental effects under disease stress (Hafez et al. 2014). Also, electrolyte leakage (EL) is an indication of increased permeability of the plasma membrane under disease stress (Omara et al. 2015).

Therefore, the aim of this investigation was to evaluate the effect of foliar application of non-traditional treatments against the wheat stem rust pathogen as well as understanding the physiological and biochemical changes in the treated wheat plants under stress of $P$. graminis $\mathrm{f}$. $\mathrm{sp}$. tritici.

\section{Materials and methods}

\section{Bacterial strains}

Bacillus subtilis, B. polymyxa, and B. megaterium used in this study were kindly obtained from Agric. Microbiology Department, Soils, Water and Environmental Res. Inst. (SWERI), Agricultural Research Center (ARC), Giza, Egypt. The strains were maintained on nutrient agar medium for $48 \mathrm{~h}$ at $28 \pm 2{ }^{\circ} \mathrm{C}$ and stored in refrigerator at $4{ }^{\circ} \mathrm{C}$ until use after Difco Manual (1985).

\section{Preparation of bacterial suspension}

Bacterial suspension was prepared by cultivating Bacillus strains on nutrient broth medium using shaking flask submerged culture. Conical flasks $(500 \mathrm{ml})$ containing $200 \mathrm{ml}$ of the respective media were inoculated with 1 $\mathrm{ml}$ bacterial inocula of $24 \mathrm{~h}$ old culture and incubated in rotary shaking incubator $(120 \mathrm{rpm})$ at $28 \pm 2{ }^{\circ} \mathrm{C}$ for $72 \mathrm{~h}$. The bacterial suspension density was adjusted to $10^{6}$ $\mathrm{cfu} / \mathrm{ml}$ (Sun et al. 2013). The obtained cell suspensions were foliar sprayed directly on the wheat plants $(100 \mathrm{ml}$ for each treatment). Foliar spraying of wheat plants was applied using the 2 applications methods, i.e., $24 \mathrm{~h}$ before inoculation and $24 \mathrm{~h}$ before and after inoculation.

\section{Natural materials}

\section{Eugenol}

Eugenol was kindly supplied by the Faculty of Pharmacy, Ain Shams University, Egypt, in the form of crude powder and used at concentration of $0.5 \mathrm{~g} / \mathrm{l}$.

\section{Artemisia cina extract}

Artemisia cina leaves were air-dried for $72 \mathrm{~h}$ at $35{ }^{\circ} \mathrm{C}$ then ground by a blender into fine powder. One hundred grams of the powder was macerated in $500 \mathrm{ml}$ of ethanol and acetone mixture (at the ratio of 1:1, v/v) by shaking for $5 \mathrm{~h}$ on an electrical shaker. Extract was filtered through sterilized filter papers and then dried over anhydrous sodium sulfate and evaporated to dryness. The residue was dissolved in ethanol 99\% (Lopa, India) to reach the desired concentrations (2\%) as described by Morsy (2010).

\section{Microscope examination}

Effect of treatments on urediniospores germination and disease symptoms

Under in vitro conditions, fresh urediniospores were sprayed on cleaned and sterilized glass slides (Nair and Ellingboe 1962). Slides were covered with a thin smear of $2 \%$ water agar then amended with different treatments. Slides were placed on V-shaped glass rods in sterilized petri-dishes with moistened filter papers. Slides were incubated at $25^{\circ} \mathrm{C}$ for $12 \mathrm{~h}$ under full light condition and microscopically examined at $\times 40$ magnification to determine the percentage of spore-germination (Reifschneider et al. 1985). Spores were considered to have germinated if a germ tube, as long as the width, was produced (Menzies and Belanger 1996). Percentages of germination were calculated for 100 spores on a slide. Three slides were examined for each treatment. Slides with water agar free from any treatment were used as control.

Meanwhile under greenhouse conditions, after symptoms appearance, the treated plants with the previous treatments and the check treatment were sampled at the 4th day, and specimens of lesions were prepared for microscopic examination. Leaves showing stem rust pustules were maintained in lactophenol on slides. Abnormality or deleterious effects on $P$. graminis were observed using light microscope and photographed.

\section{Greenhouse experiments \\ Incubation, latent periods, pustule size, and receptivity (number of pustules)}

Seeds of Gemmeiza-11 cultivar (5-7 grains) were sown in $10 \mathrm{~cm}$ plastic pots filled with clay soil $(400 \mathrm{~g})$. After 7 days from planting (seedling stage), the plants were inoculated with urediniospores (TTSPQ race) of stem rust. Seedling reaction was recorded as resistance (R) or susceptible $(\mathrm{S})$ depending on the produced infection types. The infection types, 0,$0 ; 1$, and 2 , are considered to be resistant (R) or low infection type (L), while 3 and 4 are considered to be susceptible (S) or high infection type (H) according to the scale adopted by Stakman et al. (1962) as shown in Table 1. After inoculation, the plants were treated with cell suspensions of Bacillus subtilis, $B$. 
Table 1 Wheat stem rust infection types used in disease assessment for seedling stage

\begin{tabular}{lll}
\hline Host response (class) & Infection type & Disease symptoms \\
\hline Immune & 0 & No uredia or other macroscopic sign of infection. \\
Nearly immune & $0 ;$ & No uredia but hypersensitive necrotic or chlorotic flecks present. \\
Very resistant & 1 & Small uredia surrounded by necrosis. \\
Moderately resistant & 2 & Small to medium uredia surrounded by chlorosis or necrosis. \\
Moderately susceptible & 3 & Medium-sized uredia that may be associated with chlorosis. \\
Very susceptible & 4 & Large uredia without chlorosis or necrosis or rarely necrosis. \\
Heterogeneous & $x$ & Random distribution of different variable-sized uredia on single leaf.
\end{tabular}

polymyxa and B. megaterium, Eugenol, and A. cina extract at $24 \mathrm{~h}$ before inoculation and $24 \mathrm{~h}$ before and after inoculation.

Incubation period (IP) (the number of days between inoculations to the commencement of the first pustule) was recorded. Latent period (LP) was calculated as described by Parlevliet (1975) by totaling the number of observed pustules on marked leaves every day until no more appearance of pustules. Additionally, the time between inoculation and the appearance of $50 \%$ of the pustules were recorded. In order to compare pustules size on the first leaf of susceptible plants, the length and width dimensions of 20 pustules were estimated. The method explained by Parlevliet and Kuiper (1977) was used to calculate the number of pustules per square centimeter per unit leaf area $\left(2.0 \times 0.5 \mathrm{~cm}^{2}\right)$ on the upper side of the leaves.

\section{Laboratories studies}

\section{Enzyme activities and electrolyte leakage}

The activities of antioxidant defense enzymes including catalase (CAT), peroxidase (POX), and polyphenoloxidase (PPO) were assayed in wheat treated leaves with $B$. subtilis, B. polymxa, B. megaterium, A. cinia, and Eugenol at 24, 72, and $168 \mathrm{~h}$ after inoculation. Fresh leaves $(0.5 \mathrm{~g})$ were homogenized at $4{ }^{\circ} \mathrm{C}$ and centrifuged $\left(12.000 \mathrm{rpm}, 20 \mathrm{~min}, 4{ }^{\circ} \mathrm{C}\right)$. The total soluble enzyme activities were estimated spectrophotometrically in the supernatant. PPO activity was determined according to the methods described by Malik and Singh (1980). POX activity was measured according to the procedure suggested by Hammerschmidt et al. (1982). CAT activity was measured according to Aebi (1984). Additionally, the percentage of electrolyte leakage was recorded as initial conductivity/final conductivity $\times 100 \mathrm{M}$ according to Szalai et al. (1996).

\section{GC-MS analysis}

The method of hydrolysis-methanolysis was used to obtain the methyl esters without dehydration of the $ß$-hydroxy fatty acids and to avoid the formation of the mixture of $\alpha$ - and $\beta$-monounsaturated fatty acids
(Aveldano and Horrocks 1983). Volatile compounds in the extracts were analyzed by gas chromatography and mass spectrometry. Extract solutions (0.2\%) in methanol were injected into a HP $6890 \mathrm{~N}$ gas chromatograph equipped with HP 5975 mass detector and fused silica capillary column HP5 MS (5\% phenyl methyl silicone, $30 \mathrm{~m}$ length, $0.25 \mathrm{~mm}$ i.d.). The temperature was programmed from $30(1 \mathrm{~min})$ to $230{ }^{\circ} \mathrm{C}(20 \mathrm{~min})$ at the rate of $4{ }^{\circ} \mathrm{C} / \mathrm{min}$. Detector was heated at $250{ }^{\circ} \mathrm{C}$, injector at $230{ }^{\circ} \mathrm{C}$. Helium was used as a carrier gas at 5-psi pressure. Mass spectra were obtained by electron ionization at $70 \mathrm{eV}$.

\section{Statistical analysis}

Data were statistically analyzed by analysis of variance, using software package SPSS 22. A randomized complete block design (RCBD) with 4 replicates (five pots per replicate) was used. Principle components analysis (PCA) of incubation and latent periods, infection type, pustule length, pustule width, receptivity (no. of pustule), catalase (CAT), peroxidase (POX), polyphenoloxidase (PPO), and electrolyte leakage was performed, using statistical product and service solutions (SPSS 22). The used technique of PCA was factor-loading matrix obtained from a varimax rotation with Kaiser normalization of main components.

\section{Results and discussion}

The impact of 3 tested rhizobacterial strains (B. subtilis, B. polymyxa, and B. megaterium), Eugenol, and A. cina leaves extract on patho-physiological changes of wheat plants under stem rust stress was studied under laboratory and greenhouse conditions.

\section{Microscope examination \\ Effect of the tested treatments on spore germination and disease symptoms}

The effect of whole culture of the 3 Bacillus strains, Eugenol, and $A$. cina extract on spore germination of $P$. graminis on water agar medium was shown in Fig. 1. B. subtilis and Eugenol treatments had a higher impact for inhibition of spore germination than the control (Fig. 1b, 


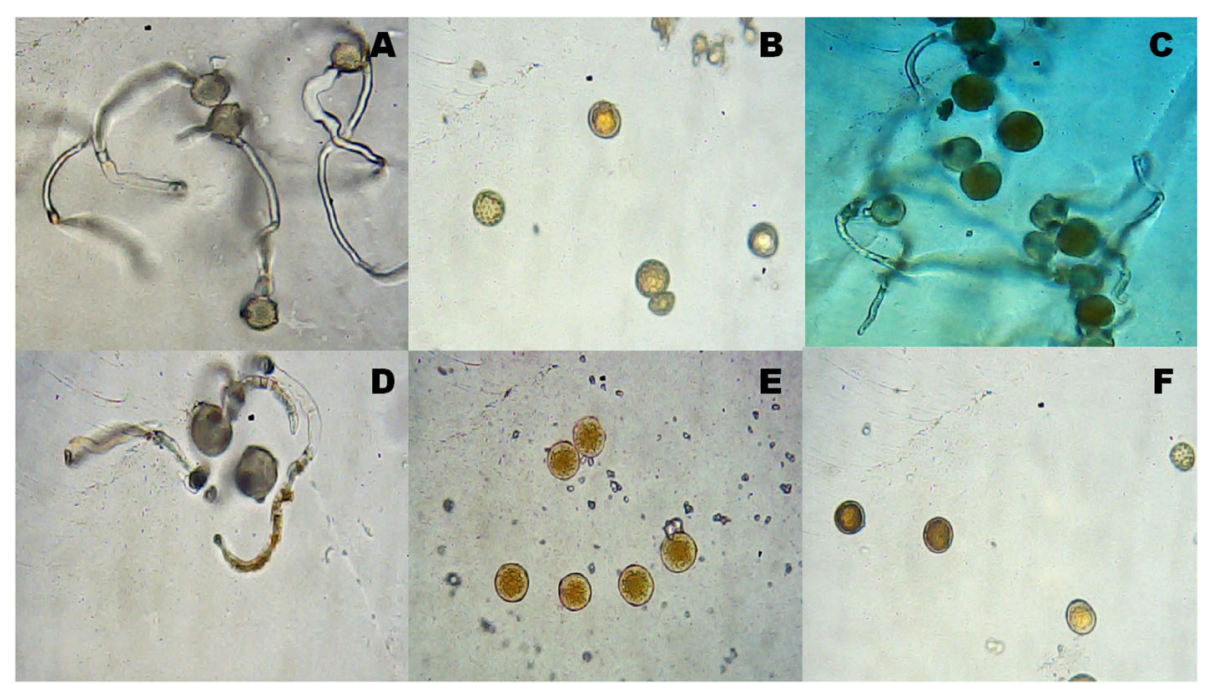

Fig. 1 Light microscopy of $P$. graminis urediniospores germination on water agar medium with five treatments. a Control (untreated), b B. subtilis, c B. megaterium, d B. polymxa, e Art. $2 \%$, and f Eugenol

f). On the other hand, spores treated with $B$. megaterium showed the highest germination percentage (Fig. 1d). Microscopic examinations of urediniospores exhibited abnormalities, lysis, collapse, and shrinking as a direct effect of the B. subtilis (b), B. polymyxa (c), B. megaterium (d), Eugenol (f), and Artemisia extract 2\% (e) compared to (a) the control treatment (Fig. 2). It is well known that some Bacillus species produce extracellular metabolites such as lipopeptides and peptides with antibiotic activity and could be used as antagonists or growth promoters (Romero et al. 2008). Swelling and enlargement of mycelium were reported using lipopeptides by modification of the fungal membrane permeability and lipid composition.
The inhibiting effect on spore germination of stem rust pathogen is mainly due to antibiosis. Bacillus spp. produce at least 66 different antibiotic components (Ferreira et al. 1991). These antifungal materials inhibited growth of the pathogenic fungi and consequently reduced the disease. $B$. subtilis inhibited the growth of a wide range of fungal species including those in the Ascomycetes and Deuteromycetes (Qiao 2006). Likewise, E1R-j strain of B. subtilis inhibited urediniospores germination and germ tubes of $P$. striiformis in wheat (Li et al. 2013). The mycelial growth of Botrytis cinerea and Sclerotinia sclerotiorum were sensitive to Eugenol (Wang et al. 2010). Also, the inhibition of P. triticina urediniospores germination in vitro was achieved by using some plant extracts, i.e., Jacaranda mimosifolia,

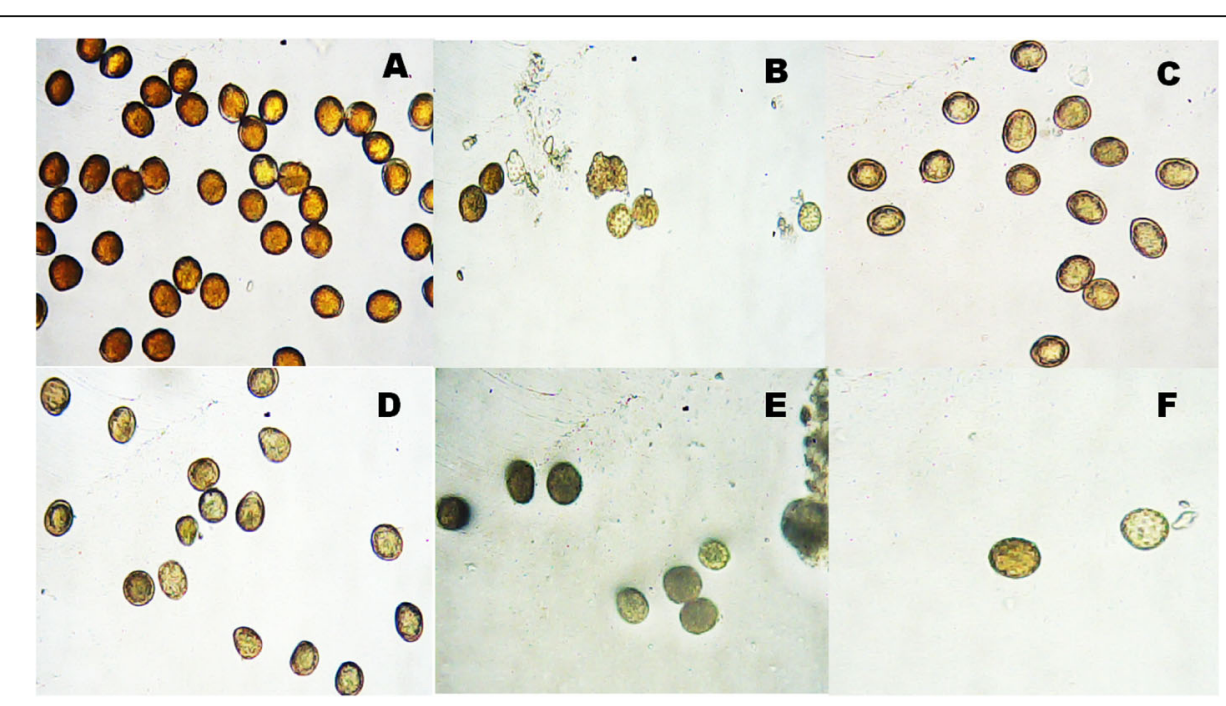

Fig. 2 Light microscopy of $P$. graminis on wheat leaves sprayed with five treatments. a Control (untreated), b $B$. subtilis, c $B$. megaterium, d $B$. polymxa, e Art. $2 \%$, and $\mathbf{f}$ Eugenol. b, c, d, and $\mathbf{f}$ Abnormalities, lysis, collapse, and shrinking of urediniospores were found in the treatments 


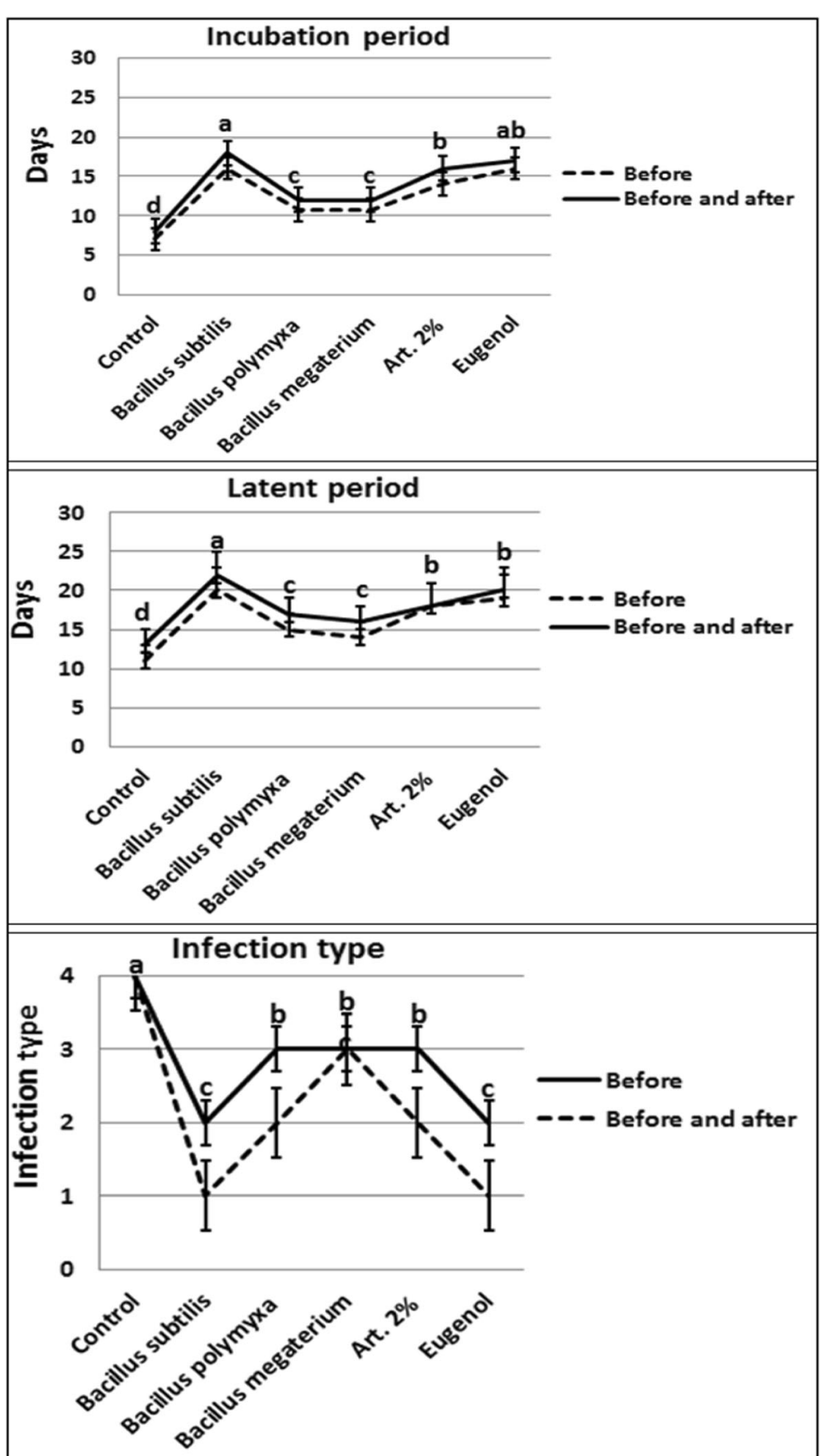

Fig. 3 Effect of three bioagents and two natural materials on stem rust development (incubation, latent periods, and infection type) at seedling stage

Thevetia peruviana, and Calotropis procera (Naz et al. 2014), while the selected treatments, i.e., Art. $2 \%+\mathrm{Zn}$, Art. $2 \%+$ Mn, Art. $2 \%+$ Fe, Art. $2 \%+$ Cu, Art. $1 \%+50 \%$ Sumi8 , and Art. $1 \%$, prevented spore germination of $P$. triticina (Omara et al. 2015). These results are in agreement with the obtained results, which clearly showed that the Bacillus strains, Eugenol, and A. cina extract significantly suppressed spore germinations of $P$. graminis on water agar medium with abnormalities and malformation of urediniospores.

\section{Greenhouse studies}

Effect of the tested treatments on incubation, latent periods, and infection type

The effects of the 3 bioagents and the 2 natural materials on stem rust development, such as incubation, 
latent periods, and infection type, were shown in Figs. 3 and 4. Different treatments gave significant differences when sprayed $24 \mathrm{~h}$ before and $24 \mathrm{~h}$ before and after inoculation of all parameters at 7 days from planting. Incubation and latent periods were increased in B. subtilis and Eugenol treatments. Besides, both treatments achieved the lowest infection type compared to the control. These results might be due to that Bacillus spp. produce several antibiotic compounds that are responsible of these changes in stem rust parameters (Ferreira et al. 1991). On the other hand, the incubation and latent periods as well as the infection type increased slowly in the B. megaterium treatment than the control treatment (Figs. 3 and 4). Likewise, the application of B. subtilis, T. viride, and plant extracts significantly increased both incubation and latent periods of leaf rust, caused by $P$. triticina f. sp. tritici (Omara et al. 2015 and 2019). Moreover, a foliar spray application at $24 \mathrm{~h}$ before and after inoculation was the best application on the seedling disease parameters, incubation and latent periods and infection type compared to application $24 \mathrm{~h}$ before inoculation.

The positive effects on both incubation and latent periods might be due to the induction of systemic resistance (ISR) as a main mechanism of plant response (Loeffler et al. 1986). Furthermore, the application of bioagents could positively alter the physical and

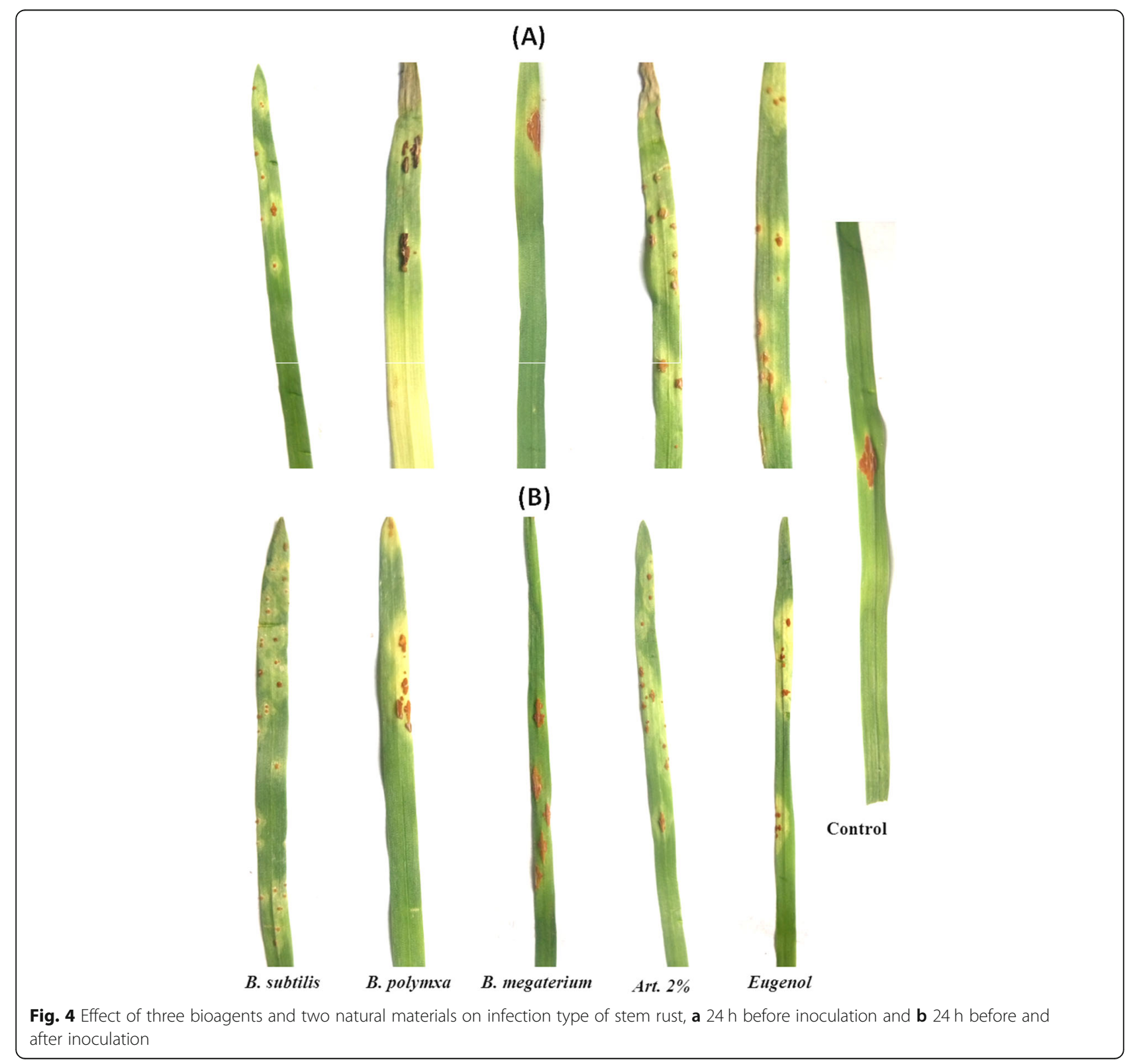


mechanical strength of cell walls and adjust the physiological and biochemical responses of wheat plants, which can enhance the biosynthesis of defense-associated molecules that play a key role in delaying the inoculation and latent period of P. graminis. Additionally, Bacillus spp. have numerous approaches to control the disease such as the production of antifungal compounds, nutrient competition, and the induction of systemic resistance (Urszula et al. 2004).
Effect of the tested treatments on pustule size and receptivity (no. of pustules) of $P$. graminis at seedling stage Figure 5 shows the reduction in pustule length, pustule width, and receptivity of $P$. graminis in different treatments. Both B. subtilis and Eugenol gave the lowest pustule length, pustule width, and receptivity than the control (untreated). In contrast, the B. megaterium treatment showed the lowest reduction in pustule length, pustule width, and receptivity. These results could be

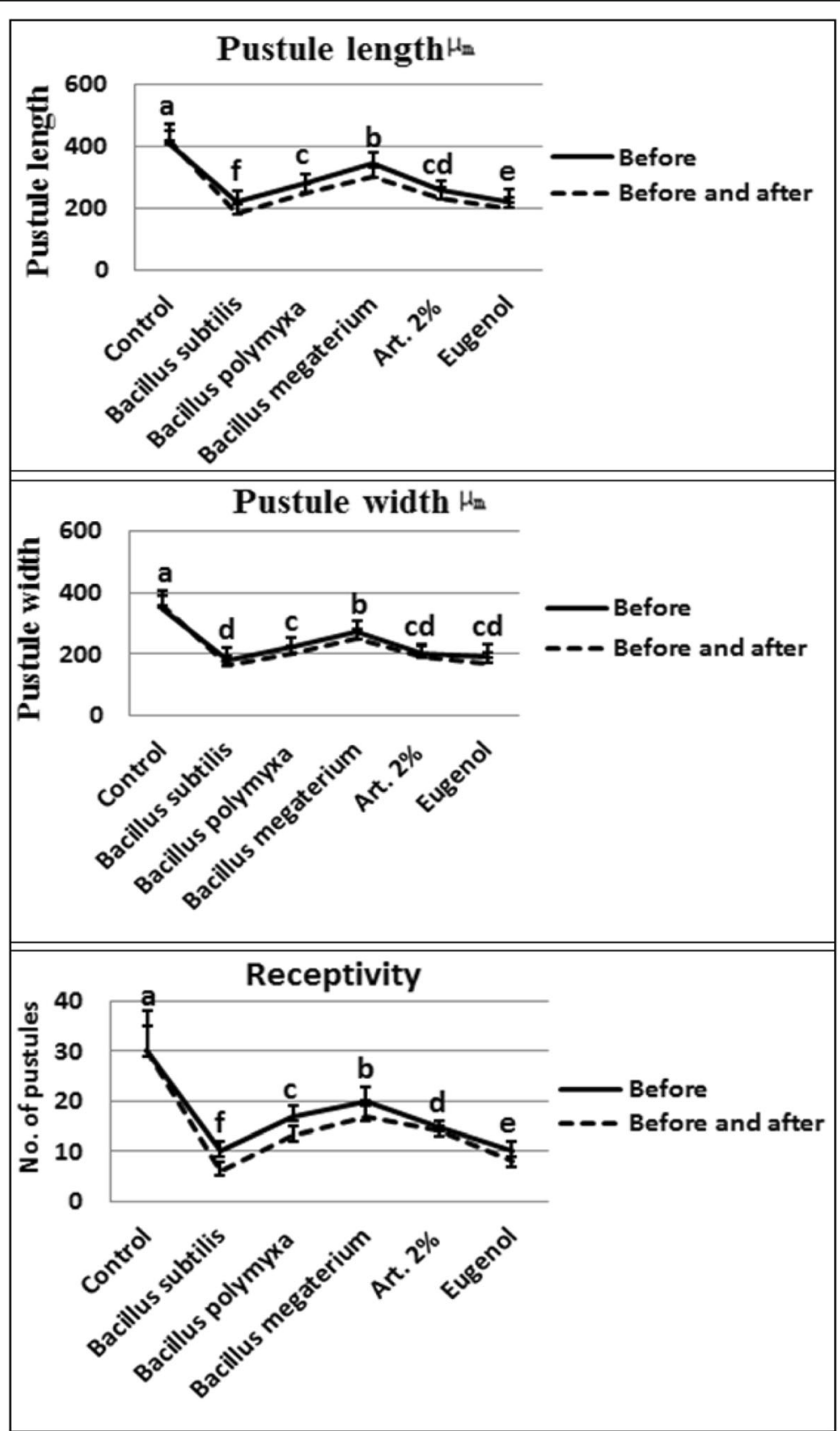

Fig. 5 Effect of treatments on pustule length and pustule width and receptivity of $P$. graminis urediniospores at seedling stage 
due to the production of antibiotics by $B$. subtilis such as bacillin, bacillomycin, bacitracin, mycosubtilin, subenolin, subsporin, and subtilin (Loeffler et al. 1986) reducing the development of the disease and pustule size. In addition, the membrane binding and permeability alteration were reported in Eugenol treatments leading to destabilization and disruption of the plasma membrane (Wang et al. 2010).

\section{Laboratory studies}

\section{Antioxidant defense enzymes and electrolyte leakage}

The activities of antioxidant defense enzymes including catalase (CAT), peroxidase (POX), and polyphenol oxidase (PPO) were displayed in Fig. 6a-c. Bacillus subtilis and Eugenol treatments resulted in a higher activity of CAT, POX, and PPO than control plants at 24,72 , and $168 \mathrm{~h}$, but the highest increase was recorded at $72 \mathrm{~h}$. These enzymes may participate in the responding defense reaction by induction of plant resistance against the pathogenic agents (Ray et al. 1998). Likewise, utilization of Bacillus spp. stimulated the enzymatic activities of chitinase, POX, and PPO against Rhizoctonia damping-off of snap bean plants (Ahmed 2016).

Catalase (CAT) as one of the oxidative enzymes plays an important role for increasing host resistance to control plant pathogens (Liau and Lin 2008). The increased activity of catalase prevented the increase of cytosolic hydrogen peroxide that creates toxic conditions leading to preventing pathogen spread and acting as a secondary signal for defense gene expression and activation of systemic acquired resistance (Neamat et al. 2016). Peroxidase is the first enzyme exhibiting changes in its activity under environmental stress (Milavec et al. 2001). Moreover, the changes in this antioxidant enzyme are known to be directly involved in the activation of plant defense responses. POX is known to catalyze the final polymerization step of lignin synthesis and is directly associated with the increased ability of systemically protected tissues for lignification (Chittoor et al. 1999). Therefore, the peroxidase activity could be used as a good indicator for plant resistance to diseases (Hameed et al. 2011). Also, PPO plays an important role in plant defense via the oxidation of endogenous phenolic compounds to the toxic quinines, which are toxic to the

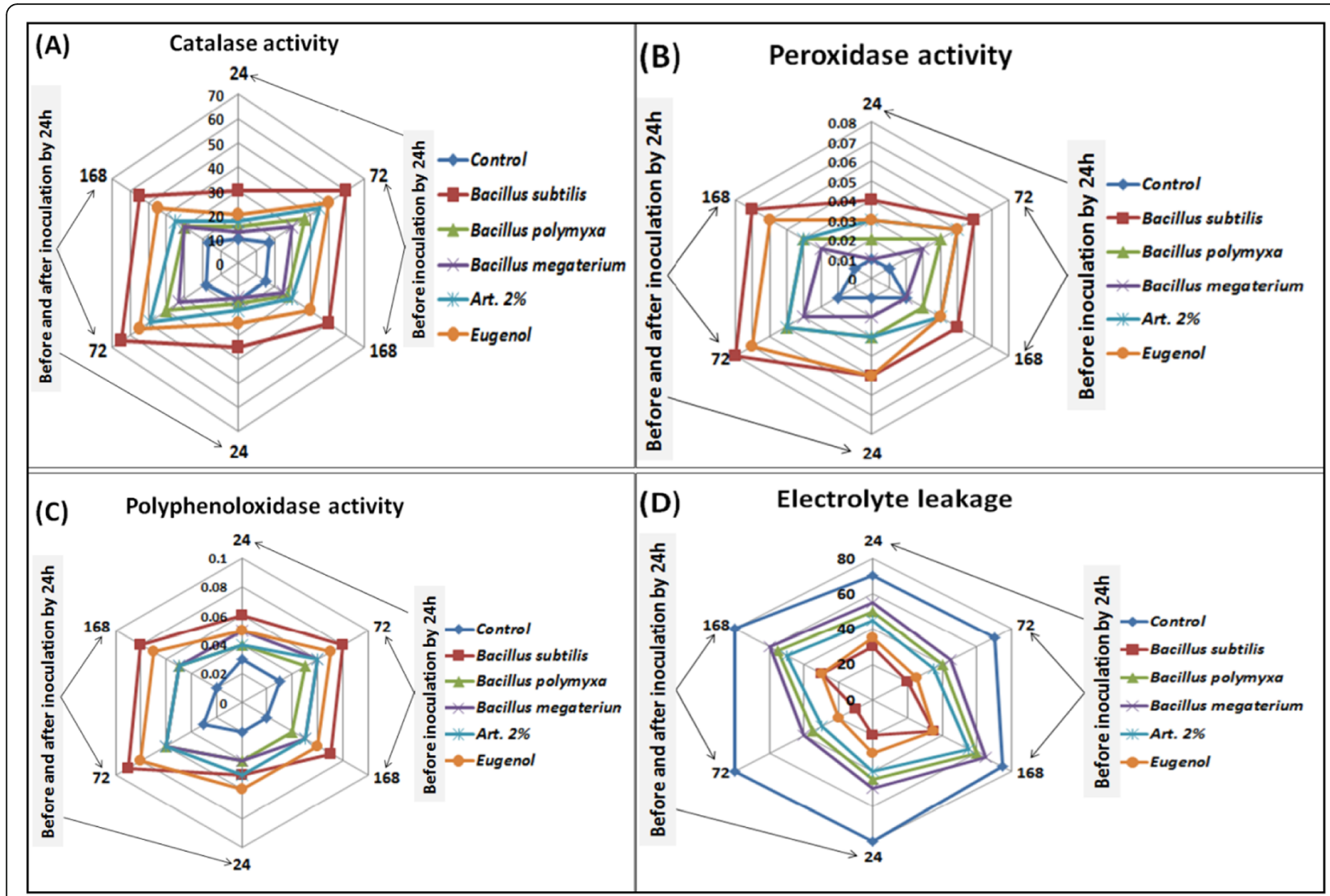

Fig. 6 Activity of catalase, peroxidase, polyphenoloxidase enzymes, and electrolyte leakage in wheat leaves infected with Puccinia graminis and treated with five treatments after 24, 72, and $168 \mathrm{~h}$ for two applications 


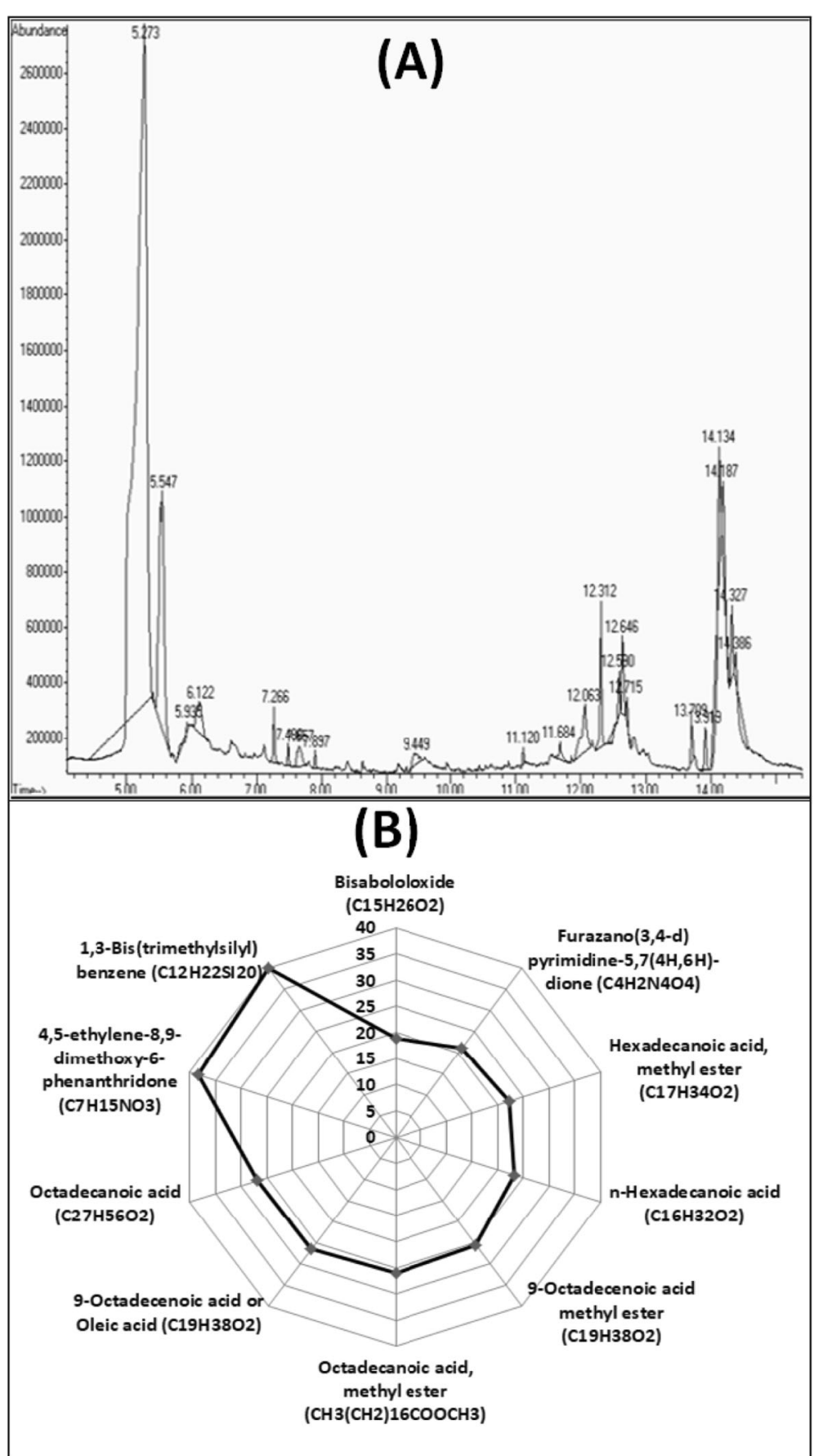

Fig. 7 Metabolites structural (a) and its molecular formula (b) extracted by GC-MS analysis of B. subtilis

invading pathogens (Thakker et al. 2011). It may also participate in the inducible defense reaction and hypersensitivity for inducing resistance of plants to fungi, viruses, and bacteria (Hanifei et al. 2013).

As for electrolyte leakage, all treatments resulted in a clear reduction in electrolyte leakage in wheat plants infected with stem rust compared to control plants (Fig. 6d). These results may be due to the effect of the pathogen on the plasma membrane in control plants that increases the permeability of the plasma membrane. $B$. subtilis and Eugenol treatments were the best in decreased electrolyte leakage compared to the untreated plants. Plant stresses such as salinity, pathogen attack, drought, heavy metals, hyperthermia, and hypothermia 
accompanies electrolyte leakage (EL) as a mechanism of defense response.

Electrolyte leakage (EL) is an indication of increased permeability of the plasma membrane in the control plants than other treatments (Fig. 6d). The plasma membrane in the treatments was not affected by the infection, and its permeability was not increased (Omara et al. 2015). EL is related to $\mathrm{K}+$ efflux from plant cells, which mediated by plasma membrane action conductance (Demidchik et al. 2014). The results were consistent with those obtained by Omara and Abdelaal (2018).

\section{Characterization of $B$. subtilis metabolites by GC-MS} analysis

Due to the performance of B. subtilis compared with other evaluated bioagents, MEMs (Micro-Electro Mechanical Systems) GC-MS technology was used to identify its active compounds. The most peak numbers and peak areas of compounds excreted by $B$. subtilis belonged to ten compounds. These compounds mostly included fatty acids known as 9-octadecanoic acid, octadecanoic acid, oleic acid, n-hexadecanoic acid, and hexadecanoic acid (Fig. 7).

Generally, numerous members of Bacillus species are known as producers of lipopeptides belonging to the
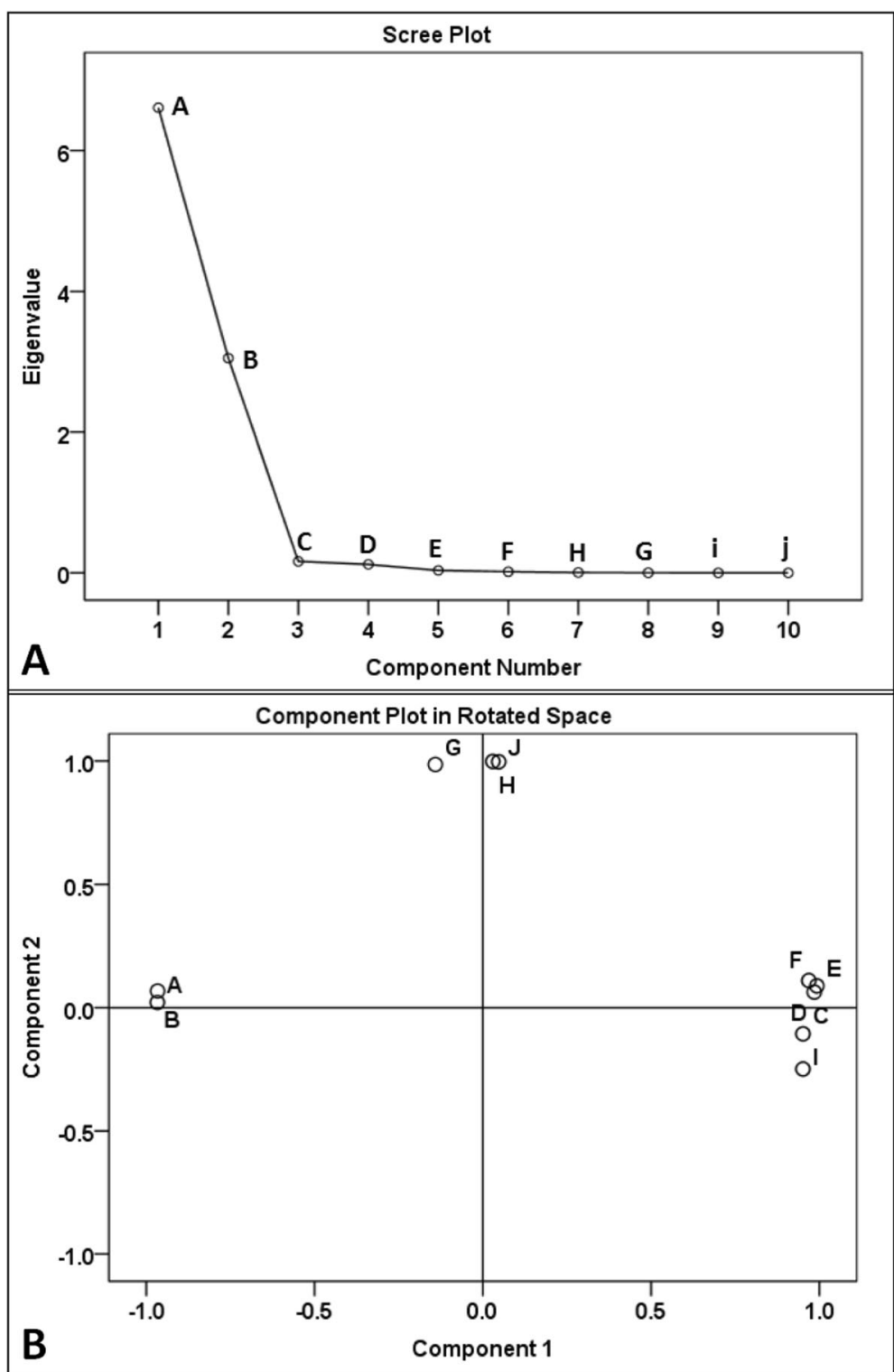

Fig. 8 The scree plot of eigenvalue (a) and loadings plot (b) for incubation and latent periods, infection type, pustule length, pustule width, catalase, peroxidase, polyphenoloxidase enzymes, and electrolyte leakage in response to wheat stem rust. $A$, incubation period; $B$, latent period; $C$, infection type; D, no. of pustule; E, pustule length; F, pustule width; G, catalase; H, peroxidase; I, polyphenoloxidase; and J, electrolyte leakage 
surfactin, iturin, and fengycin families (Zuber et al. 1993). Fengycin is an antifungal lipopeptide complex produced by B. subtilis F-29-3 (Vanittanakom and Loeffler 1986). It consists of 2 main components, fengycin A and fengycin $B$. The lipid moiety of both analogs was more variable as fatty acids and identified as anteiso-pentadecanoic acid (ai-C15), iso-hexadecanoic acid (i-C16), and nhexadecanoic acid ( $\mathrm{n}-\mathrm{C} 16)$. There is an evidence for further saturated and unsaturated residues up to C18. In the present study, these components of fatty acids were detected in supernatant analysis, using GC-MS in case of $B$. subtilis. These results were consistent with those of Belal et al. (2013) who found that the methanolic extract of $B$. subtilis contained fatty acids such as nonanoic acid, decanoic acid, dodecatrienoic acid, heptadecanoic acid, octadecanoic acid, pentadecanoic acid, hexadecanoic acid, and some of their derivatives (Belal et al. 2013).

\section{Principal component analysis (PCA)}

Principal component analysis was performed on incubation and latent periods, infection type, pustule length, pustule width, receptivity (no. of pustule), catalase (CAT), peroxidase (POX), polyphenoloxidase (PPO), and electrolyte leakage in response to artificial infection of wheat stem rust and treatment with three Bacillus strains, Eugenol, and A. cina extract (Fig. 8a, b). Interpretation of the principal components (PCs) was aided by inspection of the factor-loading matrix extracted from a varimax rotation with Kaiser normalization of main components to identify factors responsible for the grouping of the dataset. As shown from scree plot graph of eigenvalues and loadings plot (Fig. 8), these 2 components, incubation and latent periods, have eigenvalues more than one. Therefore, these 2 components were extracted and describing approximately $96.595 \%$ of total variation; the remaining was $3.405 \%$ distributed on 8 factors. So, the variation of these factors is very small and negligible. Accordingly, principal component analysis gave an evidence to the importance of incubation and latent periods, as they were considered a good and more reliable indicator for evaluation of these materials. Summing up the results, the factor-loading matrix, extracted from a varimax rotation with Kaiser normalization, gave clear evidence to the importance of all parameters in this study, especially incubation and latent periods. Similar results were previously obtained when correlation statistics were performed between different disease parameters of wheat rusts and grain yield of the studied wheat genotypes (Abu Aly et al. 2017).

\section{Conclusion}

The present study assured the promising capability of the tested microbial agents and natural materials in controlling wheat stem rust disease. Although the used chemical control surpassed biocontrol agents in the efficacy of disease inhibition, the bioagents have other important environmental advantages with high considerations. Thus, for environmental safety, further study is needed before the broad commercial use of these antagonistic microorganisms.

\section{Acknowledgements \\ The authors greatly acknowledge the staff of Department of Agricultural Botany, Faculty of Agriculture, Kafr-Elsheikh University, Kafr-Elsheikh, Egypt. The authors also thank the staff members of Wheat Diseases Research De- partment, Plant Pathology Research Institute, ARC, Egypt.}

\section{Authors' contributions}

All authors carried out the experiments and write the manuscript. All authors read and approved the final version of the manuscript.

\section{Funding}

Funding is by the authors.

Availability of data and materials

All data and materials are available.

Ethics approval and consent to participate

Ethics committee approved the research article, and all authors agree (consent) to participate in this research article.

\section{Consent for publication}

All authors participated in the work and consent for publication.

\section{Competing interests}

The authors declare that they have no competing interests.

\section{Author details}

'Plant Pathology Research Institute, Agriculture Research Center (ARC), Giza, Egypt. ${ }^{2}$ Agricultural Botany Department, Faculty of Agriculture, Kafrelsheikh University, Kafr Elsheikh 33516, Egypt.

Received: 14 April 2020 Accepted: 18 June 2020

Published online: 29 June 2020

\section{References}

Abd El-moneim Maisa L, El-Naggar DRM, Hermas GA (2011) Biological control of wheat stem rust by using two bioagents and garlic extract Bacillus spp. Egypt J Appl Sci 26(7):259-272

Abu Aly AAM, Omara Rl, Abd El-Malik Nagwa I (2017) Evaluation of new sources of resistance to wheat stripe rust (Puccinia strifformis f.sp. tritici), under Egyptian field conditions. J. Plant Prot. And path. Mansoura Univ 8(4):181-188

Aebi H (1984) Catalase in vitro. Methods Enzymol 105:121-126

Ahmed G (2016) Efficiency of some antioxidants and bioagents in controlling Rhizoctonia damping-off of snap bean. Middle East J Appl Sci 6:748-758

Aveldano MI, Horrocks LA (1983) Quantitative release of fatty acids from lipids by a simple hydrolysis procedure. J Lipid Res 24:1101-1105

Belal EB, Kamel SMH, Hassan MM (2013) Production of antimicrobial metabolites by Bacillus subtilis and their applications. Biotechnology 12:14-24

Chittoor JM, Leach JE, White FF (1999) Induction of peroxidase during defense against pathogens. In: Datta SK, Muthukrishnan S (eds) Pathogenesis- related proteins in plants. USA. CRC Press, Boca Raton, FL, pp 171-193

Demidchik V, Straltsoval D, Medvedev SS, Pozhvanov G, Sokolik A and Yurin V (2014) Stress-induced electrolyte leakage: the role of Kt-permeable channels and involvement in programmed cell death and metabolic adjustment. J Experi Bot 65(5): 1259-1270.

Difco Manual (1985) Dehydrated culture media and reagents for microbiology, 9th edn. Laboratories Incorporated Detroit, Michigan, p 364

El-Sawy MM, Omara RI, Ashmawy MA (2016) Use of natural products as fungicide alternatives against wheat stripe rust and improvement grain crop. Egy J Plant Pro Res 4(4):1-20

Ferreira JHS, Mathee FN, Thomas AC (1991) Biological control of Eutypa on grapevine by an antagonistic strain of Bacillus subtilis. Phytopathology 81: $283-287$ 
Hafez YM, Soliman NK, Saber MM, Imbab IA, Abd-Elaziz AS (2014) Induced resistance against Puccinia triticina the causal agent of wheat leaf rust by chemical inducers. Egypt J Biol Pest Cont 24(1):173-181

Hameed FE, Abood JK, Temur HA (2011) The change of peroxidase activity in three cucumber cultivars during development of powdery mildew infection. J Babylon Univ Pure App Sci 3:877-883

Hammerschmidt R, Nuckles EM, Kuć J (1982) Association of enhanced peroxidase activity with induced systemic resistance of cucumber to Colletotrichum lagenarium. Physiol Plant Pathol 20(1):73-82

Hanifei M, Dehghani H, Choukan R (2013) The role of antioxidant enzymes and phenolic compounds in disease resistance to Fusarium oxysporum f. sp. melonis race 1.2. Int. J. Gro. Plant Prod 4(8):1985-1996

Hermas GA, El-Naggar DRM, Abd El-Moinem ML, Omar MNA (2008) Biological control of wheat leaf rust using Pseudomonas fluorescens and Bacillus spp. Zagazig J Agric Res 35(4):807-823

Li H, Zhao J, Feng H, Huang L, Kang Z (2013) Biological control of wheat stripe rust by an endophytic Bacillus subtilis strain E1R-j in greenhouse and field trials. Crop Prot 43:201-206

Liau CY, Lin CS (2008) Detection of chitinolytic enzymes in Ipomoea batatas leaf extract by activity staining after gel electrophoresis. J Chin Chem Soc 55(3): 678-681

Loeffler W, Tschen JSM, Vanittanakom N, Kugler M, Knorpp E, Hsieh TF, Wu TG (1986) Antifungal effects of bacilysin and fengymycin from Bacillus subtilis F293: a comparison with activities of other bacillus antibiotics. J Phytopathol 115:204-213

Malik CP and Singh MB (1980) In: Plant enzymology and histo-enzymology. Kalyani Publishers. Indian and Printed in Navin. Shanndara. Delhi. pp. 54-56.

Menzies JG, Belanger RR (1996) Recent advances in cultural management of diseases of greenhouse crops. Can J Plant Pathol 18(2):186-193

Milavec M, Ravnikar M, Kovač M (2001) Peroxidases and photosynthetic pigments in susceptible potato infected with potato virus YNTN. Plant Physiol Biochem 39(10):891-898

Morsy SA (2010) Studies on fungicidal activity of some fungicides, plant extracts and bioagents against both powdery and downy mildew diseases on cucumber and squash. Ph.D., Thesis Fac. of Agric. Kafrelsheikh Univ., Egypt, pp.55.

Nair KRS, Ellingboe AH (1962) A method of controlled inoculations with condiospores of Erysiphe graminis var. tritici. Phytopatholology 52: 417.

Naz R, Bano A, Wilson NL, Guest D, Roberts TH (2014) Pathogenesis-related protein expression in the apoplast of wheat leaves protected against leaf rust following application of plant extracts. Phytopatholology 104(9):933-944

Neamat AK, Abou-Zeid NM, Noher AM, Abbas MS, Sobhy HM (2016) Enzyme activity and biochemical changes associated with induction of systemic resistance of faba bean against damping off disease. Egyptian J Biol Pest Cont 26(2):395-404

Omara Rl, Abd El-Malik Nagwa I, Abu Aly AA (2017) Inheritance of stem rust resistance at adult plant stage in some Egyptian wheat cultivars. Egypt J Plant Breed 21(2):261-275

Omara Rl, Abdelaal KAA (2018) Biochemical, histopathological and genetic analysis associated with leaf rust infection in wheat plants (Triticum aestivum L.). Physiol Mol Plant Pathol 104:48-57

Omara Rl, El-Kot GA, Fadel Fawzya M, Abdelaal KAA, Saleh Eman M (2019) Efficacy of certain bioagents on patho-physiological characters of wheat plants under wheat leaf rust stress. Physiol Mol Plant Pathol 106:102-108

Omara RI, Kamel SM, Hafez YM, Morsy SZ (2015) Role of non-traditional control treatments in inducing resistance against wheat leaf rust caused by Puccinia triticina. Egyp J Biol Pest Cont 25(2):335-344

Parlevliet JE (1975) Partial resistance of barley to leaf rust. Puccinia hordei I effect of cultivars and development stage on latent period Euphytica 24:21-27

Parlevliet JE, Kuiper HJ (1977) Partial resistance of barley to leaf rust. Puccinia hordei IV Effect of cultivars and development stage on infection frequency Euphytica 26:249-255

Qiao HP (2006) Biological control of take-all disease of wheat by endophytic bacteria. Ph.D. thesis, Northwest A\&F Univ., Yangling, Shaanxi, China (in (hinese)

Ray H, Douches DS, Hammerschmidt R (1998) Transformation of potato with cucumber peroxidase: expression and disease response. Physiol Mol Plant Pathol 3:93-103

Reifschneider FJB, Bolitexa LS, Occhiena EM (1985) Powdery mildew of melon (Cucumis melo) caused by Sphaerotheca fuliginea in Brazil. Plant Dis 69:1069-1070

Romero D, Vicente De A, Zeriouh H, Cazorla FM, Fernández-Ortuño D, Torés JA Pérez-García A (2008) Evaluation of biological control agents for managing cucurbit powdery mildew on greenhouse-grown melon. Plant Pathol 751(56):976-986

Stakman EC, Stewarit DM and Loegering WQ (1962) Identification of physiologic races of Puccinia graminis tritici. ARS. USDA, Agric Res Serv Bull E-617 pp. 53

Sun ZB, Yuan XF, Zhang H, Wu LF, Liang C, Feng YJ (2013) Isolation, screening and identification of antagonistic downy mildew endophytic bacteria from cucumber. Eur J Plant Pathol 137:847-857

Szalai G, Janda T, PaÂldi E, Szigeti Z (1996) Role of light in post-chilling symptoms in maize. J Plant Physiol 148:378-383

Thakker JN, Patel P, Dhandhukia PC (2011) Induction of defence related enzymes in susceptible variety of banana: role of fusarium-derived elicitors. Arch Phytopathol Plant Prot 44(20):1976-1984

Urszula W, Barbara M, Monika B, Zofia KK (2004) Biological control of winter wheat pathogens by bacteria. Acta Fytotechnica et Zootechnica 7(1):349-350

Vanittanakom N, Loeffler W (1986) Fengycin-a novel antifungal lipopeptide antibiotic produced by Bacillus subtilis F-29-3. J Antibiotics 7:888-900

Wang C, Zhang J, Chen H, Fan Y, Shi Z (2010) Antifungal activity of eugenol against Botrytis cinerea. Tropical Plant Pathol 35(3):137-143

Zuber P, Nakano MM, Marahiel MA (1993) Peptide antibiotics. In: Sonenshein AL, Hoch JA, Losick R (eds) Bacillus subtilis and other gram-positive bacteria. American Society for Microbiology, Washington, D.C., pp 897-916

\section{Publisher's Note}

Springer Nature remains neutral with regard to jurisdictional claims in published maps and institutional affiliations.

\section{Submit your manuscript to a SpringerOpen ${ }^{\circ}$ journal and benefit from:}

- Convenient online submission

- Rigorous peer review

- Open access: articles freely available online

High visibility within the field

- Retaining the copyright to your article

Submit your next manuscript at $>$ springeropen.com 